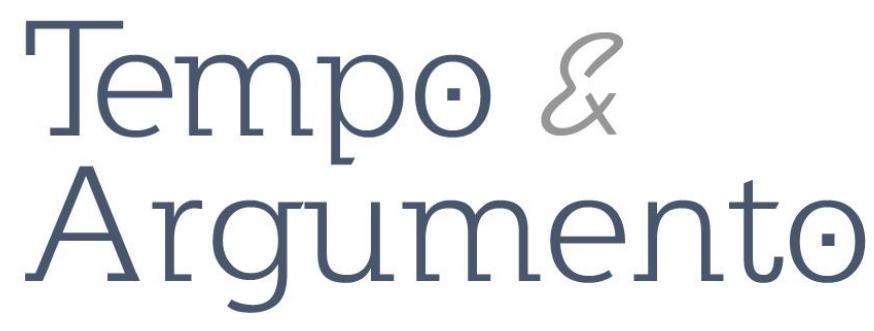

\title{
Variações do mesmo tema sem sair do tom: imprensa, Comissão Nacional da Verdade e a Lei da Anistia*
}

\begin{abstract}
Resumo
Este artigo objetiva investigar o papel da imprensa no debate público em torno da Comissão Nacional da Verdade (CNV), a partir da análise dos editoriais publicados sobre o tema pelos jornais Folha de São Paulo, O Globo e O Estado de São Paulo. Busco compreender de que maneira esses jornais participaram das controvérsias públicas sobre as "memórias conflitantes" da ditadura e da transição democrática, enquadrando determinadas interpretações e representações sobre esse passado. Apesar de algumas diferenças, é possível perceber um posicionamento comum dos editoriais desses jornais, que se aproximam no sentido de enquadrar o debate público sobre a CNV com o intuito de defender a Lei da Anistia, de 1979, se contrapondo à sua revisão e à punição daqueles que praticaram violações aos direitos humanos como agentes do Estado.
\end{abstract}

Palavras-chave: Comissão Nacional da Verdade. Memórias.

Imprensa. Enquadramento. Lei da Anistia.

\section{Fernando Perlatto}

Doutor em Sociologia pela Universidade do Estado do Rio de Janeiro (UERJ). Professor do Departamento de História da Universidade Federal de Juiz de Fora (UFJF). Juiz de Fora, MG - BRASIL fperlatto@yahoo.com.br orcid.org/0000-0003-4301-0826

\section{Para citar este artigo:}

PERLATTO, Fernando. Variações do mesmo tema sem sair do tom: imprensa, Comissão Nacional da Verdade e a Lei da Anistia. Tempo e Argumento, Florianópolis, v. 11, n. 27, p. 78 - 100, maio/ago. 2019.

DOI: $10.5965 / 2175180311272019078$

http://dx.doi.org/10.5965/2175180311272019078

\footnotetext{
* O autor agradece à Fundação de Amparo à Pesquisa de Minas Gerais (FAPEMIG) pelo apoio à pesquisa As controvérsias públicas em torno da Comissão Nacional da Verdade: ditadura, história e memória, financiada pelo Edital Universal, que deu origem a este artigo.
} 


\title{
Variations on a theme without leaving the tone: press, National Truth Commission and the Amnesty Law
}

\begin{abstract}
This article aims to investigate the role of the press in the public debate around the National Truth Commission (CNV), based on the analysis of the editorials published about this subject by the newspapers Folha de São Paulo, O Globo and $O$ Estado de São Paulo. It seeks to understand how these newspapers took part in the public controversies about the "conflicting memories" of the dictatorship and the democratic transition, framing certain interpretations and representations about this past. Despite some differences, it is possible to perceive a common position of these editorials, which have similar approaches in the sense of framing the public debate on the CNV in order to support the Amnesty Law, of 1979, in opposition to its revision and to the punishment for those who committed human rights violations as agents of the State.
\end{abstract}

Keywords: National Truth Commission. Memories. Press. Framing. Amnesty Law.

No dia 16 de maio de 2012, em cerimônia realizada no Palácio do Planalto, com a presença de quatro ex-presidentes da República que governaram o Brasil desde o início do processo de redemocratização do país - José Sarney, Fernando Collor de Mello, Fernando Henrique Cardoso e Luiz Inácio Lula da Silva -, a então presidenta, Dilma Rousseff, fez um discurso que marcava a instalação da Comissão Nacional da Verdade (CNV) e o início dos trabalhos voltados para a investigação de crimes e de violações aos direitos humanos ocorridos no período entre 1946 e 1988, com ênfase especial sobre os vinte e um anos de ditadura militar, entre 1964 e 1985. Dilma destacou em sua fala: 
Embora saibamos que regimes de exceção sobrevivem pela interdição da verdade, temos o direito de esperar que, sob a democracia, a verdade, a memória e a história venha à superfície e se torne conhecidas, sobretudo, para as novas e as futuras gerações. (...). Ao instalar a Comissão da Verdade não nos move o revanchismo, o ódio ou o desejo de reescrever a história de uma forma diferente do que aconteceu, mas nos move a necessidade imperiosa de conhecê-la em sua plenitude, sem ocultamentos, sem camuflagens, sem vetos e sem proibições. (O Globo, 17/05/2012, p. 4)

Durante os dois anos seguintes, até a publicação do Relatório Final da CNV, em dezembro de 2014, os sete membros que compuseram a CNV trabalharam com o apoio de mais de duzentos colaboradores e pesquisadores, investigando e esclarecendo as violações de direitos humanos ocorridas durante o período da ditadura ${ }^{1}$. Ainda que a CNV não tenha se constituído a partir de um vazio institucional, tendo em vista a existência de iniciativas importantes de governos anteriores no que concerne à proposição de políticas voltadas para a justiça de transição, seu envio como projeto de Lei ao Congresso Nacional pelo presidente Lula em 2010 - respondendo às reivindicações de familiares de mortos e desaparecidos, consubstanciada na $11^{\mathrm{a}}$ Conferência Nacional de Direitos Humanos e no $3^{\circ}$ Programa Nacional de Direitos Humanos -, bem como a aprovação do projeto de Lei $\mathrm{n}^{\circ}$ 12.528, em 18 de novembro de 2011 e a instalação da CNV em 2012, marcaram uma nova etapa no debate acerca das políticas públicas de memória do Brasil.

A instalação da CNV, a realização de seus trabalhos e, sobretudo, a publicação do Relatório Final provocaram uma série de debates e controvérsias públicas, envolvendo diferentes setores da sociedade, como familiares de mortos e desaparecidos, militantes dos direitos humanos, políticos, intelectuais, representantes de órgãos do Estado e da sociedade civil, assim como segmentos associados às Forças Armadas. O que estava em jogo, em grande medida, era a disputa sobre os sentidos e significados do passado, ou, dito em outros termos, o embate sobre as memórias públicas da ditadura militar. Essas controvérsias no tempo presente tiveram, na imprensa, um locus importante de

\footnotetext{
${ }^{1}$ A CNV foi composta por sete membros, nomeados pela presidenta Dilma Rousseff. Quando da instalação da comissão, em 2012, assumiram como conselheiros os membros: Claudio Lemos Fonteles, Gilson Langaro Dipp, Jose Carlos Dias, José Paulo Cavalcanti Filho, Maria Rita Kehl, psicanalista e jornalista; Paulo Sergio Pinheiro e Rosa Maria Cardoso da Cunha. Em outubro de 2012, Gilson Dipp se afastou por problemas de saúde e em junho de 2013, Claudio Fonteles renunciou ao cargo, sendo substituído por Pedro Bohomoletz de Abreu Dallari.
} 
manifestação, tendo esta se transformado em uma arena pública de debates fundamental em torno das memórias sobre esse passado. A grande imprensa, especialmente, se conformou como um ator importante nessas disputas sobre o passado, vocalizando ideias, defendendo pontos de vista e buscando "enquadrar" a forma como o debate sobre o passado transcorreu na esfera pública.

Este artigo objetiva, precisamente, refletir sobre o papel da imprensa nas controvérsias públicas em tono da Comissão Nacional da Verdade. A partir da análise dos editoriais publicados sobre o tema por três jornais de grande circulação no país - Folha de São Paulo, O Globo e O Estado de São Paulo ${ }^{2}$-, procuro compreender de que forma esses órgãos da imprensa buscaram intervir no debate público sobre as memórias da ditadura, enquadrando determinadas visões e perspectivas sobre o passado e o processo de transição à democracia, enquadramento este que encontra na defesa da Lei da Anistia, de 1979, seu eixo principal de sustentação³. A hipótese que procuro explorar é a de que, a despeito de pequenas variações nos posicionamentos dos três jornais, expostos em seus editoriais, é possível perceber um tom semelhante, que, de maneira geral, buscou enquadrar o debate sobre a CNV na esfera pública, de sorte a evitar que os embates em torno do tema pudessem levar a uma discussão mais aprofundada sobre as possibilidades da revisão da Lei da Anistia e a uma possível punição daqueles que praticaram violações aos direitos humanos como agentes do Estado.

Até mesmo pelo fato de ter sido constituída há poucos anos e por ter finalizado seus trabalhos recentemente, poucas pesquisas mais sistemáticas foram desenvolvidas sobre a Comissão Nacional da Verdade. Os estudos já produzidos têm privilegiado enfoques diversos, tais como a relação da comissão com outros processos de justiça de transição, a análise da composição da CNV e da dinâmica de seu funcionamento, assim como seus sentidos e significados nas políticas de memória sobre a ditadura, sobretudo

\footnotetext{
${ }^{2}$ A escolha destes três jornais se justifica pelo fato de se constituírem como periódicos que possuem ampla audiência no país. De acordo com pesquisa realizada pelo Instituto Verificador de Circulação (IVC), em 2018, os jornais Folha de São Paulo, O Globo e O Estado de São Paulo consolidaram-se entre aqueles veículos impressos de maior tiragem e de maior número de assinantes digitais.

3 A noção de "enquadramento" para pensar as disputas públicas de memória se ancora no diálogo com diversos autores que buscaram refletir sobre essa temática a partir de ângulos diversos, com destaque para: POLLAK (1989), TODOROV (2000), HUYSSEN (2000; 2014).
} 
pensada em uma perspectiva comparativa com outros contextos que vivenciaram experiências de regimes autoritários (BAUER, 2017; MACIEL, 2014; NEVES; 2012; PEREIRA, 2015; PERLATTO; HOLLANDA, 2017;). Contudo, um campo que ainda merece maior atenção por parte da bibliografia especializada, diz respeito aos debates públicos que tiveram lugar na imprensa em torno da Comissão Nacional da Verdade. Desde o momento inicial da constituição de um grupo de trabalho para a elaboração de um projeto de lei orientado para a criação da comissão, em 2010, até a publicação do Relatório Final, em 2014, a CNV e todas as questões a ela relacionadas produziram controvérsias públicas variadas, que polarizaram debates e discussões entre diferentes segmentos da sociedade brasileira sobre as características da ditadura civil-militar e acerca dos processos que conduziram à transição para a democracia.

De maneira resumida, é possível dizer que os debates públicos em torno da Comissão Nacional da Verdade estiveram relacionados a diferentes aspectos, tais como, a necessidade ou não da instalação de uma comissão com o perfil da CNV para investigar violações dos direitos humanos praticados no Brasil; de que maneira seria composta a comissão e quais os critérios utilizados para a escolha dos seus membros; qual seria o alcance do período a ser investigado pela CNV, devendo ele se restringir à ditadura civilmilitar de 1964 a 1985, ou os trabalhos deveriam se estender, abarcando também o período da ditadura do Estado Novo, de 1937 a 1945; qual seria o prazo de funcionamento dos trabalhos da Comissão e se este tempo seria suficiente para o desenvolvimento das atividades anunciadas. Porém, as principais controvérsias públicas em torno da CNV estiveram associadas ao alcance jurídico-político dos trabalhos da comissão: deveria ela ter apenas um caráter de investigação e pesquisa sobre o período de repressão, ou poderia também propor medidas orientadas para a revisão da Lei da Anistia, de 1979, de modo a instituir processos criminais contra o Estado e contra indivíduos que praticaram crimes contra os direitos humanos? Este artigo está interessado em investigar de que maneira os debates em torno dessa questão se fizeram presentes na imprensa brasileira, nas controvérsias públicas em torno da CNV.

Para proceder a esta análise, o texto está dividido em duas partes: na primeira, o intuito será o de realizar uma reflexão mais ampla sobre a imprensa e seu papel no 
sentido de promover, na esfera pública, determinados enquadramentos em torno de memórias públicas sobre o passado, de modo geral, e sobre a ditadura, em particular; na segunda parte, buscarei, mediante a análise de editoriais, investigar de forma mais sistemática os posicionamentos dos jornais Folha de São Paulo, O Globo e O Estado de São Paulo em torno da instalação e dos trabalhos da CNV, bem como da publicação de seu “Relatório Final”. O intuito será o de demonstrar de que maneira, não obstante algumas variações, todos eles construíram argumentos em um mesmo tom, que buscou enquadrar o debate na esfera pública e se opor a qualquer postura considerada revanchista, que implicasse na revisão da Lei da Anistia.

\section{Imprensa, enquadramento de memórias e ditadura}

Um dos campos que têm sido mais privilegiados pelos estudos dedicados à compreensão do golpe civil-militar de 1964 e da ditadura então instalada no país, se relaciona com o papel da imprensa ao longo desse período. Se, de um lado, os últimos anos testemunharam a profusão de trabalhos interessados em investigar a censura que se abateu sobre determinados setores da imprensa (AQUINO, 1999; FICO, 2002); de outro, têm se expandido pesquisas orientadas para apresentar outras dimensões das relações entre os governos militares e os órgãos da imprensa, com o intuito de se destacar que, ao lado da censura e da autocensura, e diferentemente da construção de uma memória sustentada na ideia de resistência, havia também relações de apoio e de colaboração de segmentos da imprensa com a ditadura, não apenas durante o golpe de 1964, mas no decorrer do regime, inclusive por parte de entidades como a Associação Brasileira de Imprensa (ABI) (KUSHNIR, 2004; MOTTA, 2017; ROLLEMBERG, 2010;). Ao longo dos últimos anos, novos trabalhos vêm buscando investigar de que maneira, já no contexto da transição e da democracia, foram construídas pela imprensa representações diversas sobre a ditadura civil-militar no Brasil e sobre o processo de transição (BIROLI, 2009; CARVALHO, 2015; NAPOLITANO, 2017). A grande imprensa, nessa perspectiva, compreendida como "ator político", nos termos de Maria Helena Capelato (2014), tem se configurado como uma fonte importante para a conformação de determinadas visões e representações sobre a ditadura e a transição democrática no tempo presente. 
Paralelamente ao avanço das pesquisas desenvolvidas no campo historiográfico que vêm buscando investigar as relações entre imprensa e ditadura, tem-se ampliado, de forma cada vez mais significativa, em outros campos de investigação, trabalhos dedicados a refletir de que maneira a imprensa tem atuado no sentido de pautar e enquadrar debates e controvérsias públicas que têm curso em uma determinada sociedade. Diversos estudos têm procurado destacar que, apesar do discurso ancorado em uma pretensa imparcialidade e neutralidade, os órgãos de imprensa detêm um papel seletivo central no processo de determinação das agendas e de enquadramento dos debates em torno de questões públicas, acabando por conferir maior destaque e visibilidade a certas temáticas e assuntos e a determinados pontos de vista em detrimento de outros, contribuindo decisivamente para a forma como certas temáticas são debatidas na esfera pública. Esses trabalhos vêm buscando chamar a atenção para a importância da imprensa não apenas no enquadramento do debate público em torno de pautas diversas, mas também na administração do espaço no qual se processa esse debate (DEARING; ROGERS, 1996; FERES JR et. al, 2013; MCCOMBS; SHAW, 1972; MIGUEL; BIROLI, 2010).

Além das notícias informativas, das reportagens, dos textos opinativos e das cartas dos leitores, os jornais impressos da grande mídia, em geral, possuem um espaço específico reservado para a manifestação pública de suas respectivas opiniões a respeito de temáticas diversas. Este espaço, chamado de editorial e, publicado diariamente, aborda, na maioria das vezes, a partir de uma perspectiva particular, assuntos que ganharam destaque e visibilidade na esfera pública, no momento mesmo em que aquele artigo é escrito. Trata-se de textos nos quais os editores dos jornais expõem de forma mais aberta e explícita seus posicionamentos e opiniões sobre temas variados, tendo em vista as orientações políticas e ideológicas mais gerais que, a despeito do discurso da imparcialidade, orientam aqueles órgãos de imprensa. Os editoriais assumem um papel importante no sentido de darem o tom mais geral da forma como aquele órgão da imprensa aborda determinada temática, privilegiando ou secundarizando certas questões. Esses espaços acabam por misturar "a autoridade da opinião parcial com a autoridade do capital jornalístico" (FERES JR et. al, 2013, p. 15) e, a partir da leitura desses 
textos, é possível compreender de que maneira um jornal enquadra determinada temática ou assunto.

É interessante colocar esses dois campos de investigação - as pesquisas historiográficas dedicadas à compreensão da relação entre imprensa e ditadura, de um lado; e os trabalhos voltados para a investigação sobre o caráter seletivo da imprensa na administração do debate público, de outro - em conexão com os estudos que vêm sendo realizados ao longo dos últimos anos em torno da inquirição acerca da relação entre as mídias, as disputas de memórias e dos usos públicos do passado (HUYSSEN, 2000; LEE; NINAN, 2012; NEIGGER et. al, 2011). O intuito do estabelecimento desse diálogo é o de refletir de que maneira a grande imprensa - em especial, na produção de seus editoriais atua no processo de "enquadramento" de determinadas memórias sobre o passado, a partir das interpretações e das representações construídas sobre períodos históricos específicos.

Ainda que a maior parte dos editoriais publicados pelos jornais seja direcionado a debates sobre assuntos contemporâneos, em determinados momentos, motivados por controvérsias públicas em torno do tempo presente, a imprensa acaba por redirecionar sua atenção para a discussão a respeito de temáticas do passado, construindo determinadas interpretações e representações acerca de períodos históricos específicos, a exemplo do que ocorreu quando da publicação do polêmico editorial da Folha de São Paulo, em 17 de fevereiro de 2009, que chamou a ditadura brasileira de "ditabranda" (Folha de São Paulo, 17/02/2009, p. A2), e do editorial publicado pelo jornal O Globo em $1^{\circ}$ de setembro de 2013, quando, pela primeira vez, esse órgão da imprensa reconheceu publicamente o erro pelo apoio dado ao golpe de 1964 e à ditadura que então se seguiu (O Globo, 01/09/2013, p. 15). Editoriais como esses, muitas vezes, impulsionam novas discussões públicas sobre o tempo presente e sobre o passado, evidenciando o quanto o enquadramento de "eventos traumáticos" (FICO, 2012) relacionados ao passado provocam variadas disputas e controvérsias na esfera pública em torno da memória no tempo presente.

Parto, portanto, do pressuposto segundo o qual a "grande imprensa", a despeito de seu discurso de imparcialidade, se coloca como um ator fundamental nas disputas 
públicas de "memórias conflitantes" sobre o passado, em especial na construção de determinados "enquadramentos" de períodos históricos específicos ${ }^{4}$. Não obstante a existência de memórias conflitantes, a mídia - sobretudo quando possui visão homogênea a respeito de determinado assunto -, a partir da construção de enquadramentos específicos, desempenha papel relevante no sentido de conferir maior destaque a certas representações do passado, contribuindo para conformar aquilo que Marcos Napolitano (2017, p. 348) chamou de "memória hegemônica" relacionada a determinado período histórico. Na próxima seção, buscarei analisar de que maneira, durante os trabalhos da CNV, os editoriais relacionados à temática e publicados por três jornais de grande circulação no país - O Globo, Folha de São Paulo e O Estado de São Paulo - construíram interpretações semelhantes em relação à ditadura e ao processo de transição e, que, apesar de pequenas diferenças, se aproximavam na construção de um determinado enquadramento em defesa da Lei da Anistia de $1979^{5}$.

\section{"Grande imprensa", CNV e a Lei da Anistia}

Ainda que os debates em torno da revisão da Lei da Anistia, de 1979, não tenham se iniciado em tempos recentes, atravessando o processo de redemocratização do país e a elaboração da Constituição de 1988, não restam dúvidas de que, ao longo dos últimos anos, ele ganhou novos contornos ${ }^{6}$. A criação da Comissão Especial sobre Mortos e Desaparecidos Políticos, em 1995, o estabelecimento da Comissão da Anistia em 2002 e, sobretudo, o julgamento por parte do Supremo Tribunal Federal (STF) da Ação de

\footnotetext{
4 O termo "memórias conflitantes" se ancora na crítica realizada por Andreas Huyssen ao conceito de "memória coletiva", de Maurice Halbwachs: "A mudança de perspectiva que proponho, (...), tem por premissa nosso abandono do conceito de memória coletiva mais ou menos estável de um grupo ou nação como um ideal, muito menos como descrição de qualquer realidade histórica. Em vez disso, parto da observação de que todos os fenômenos da memória costumam ser conflituosos e estar em fluxo constante no tempo" (HUYSSEN, 2014, p. 181).

${ }^{5} \mathrm{Na}$ análise realizada na próxima seção, dediquei especial atenção aos editoriais publicados a partir de 2009, quando ocorreu uma enorme repercussão pública em torno do $\mathrm{PNDH}-3$, que previa a criação de uma Comissão da Verdade. Até o momento da publicação do Relatório Final da CNV, foram analisados editoriais dos jornais selecionados que discutiam direta ou indiretamente os trabalhos da Comissão, que, de alguma maneira, abordavam temáticas vinculadas à ditadura inaugurada em 1964 e à Lei da Anistia de 1979.

6 Sobre as controvérsias em torno da "justiça de transição", de modo geral, e da Lei da Anistia, em particular, ver, entre outros: AARÃO REIS FILHO (2010); BARAHONA DE BRITO (2013); RODEGHERO (2014); SCHNEIDER (2018).
} 
Descumprimento de Preceito Fundamental (ADPF) 153, em 2010, impulsionaram controvérsias e debates públicos importantes em torno da Lei da Anistia de 1979, mobilizando diferentes entidades e segmentos sociais e políticos. A publicação do Plano Nacional de Direitos Humanos (PNDH-3), que previa a criação de uma Comissão da Verdade, e a aprovação e o início, de fato, do funcionamento da CNV, contudo, provocaram uma intensificação das controvérsias públicas que diziam respeito à Lei da Anistia, na medida em que diferentes atores vislumbravam a possibilidade real de que a lei fosse revisada, permitindo-se, assim, a punição daqueles que cometeram crimes contra os direitos humanos em nome do Estado brasileiro?.

$\mathrm{O}$ artigo $1^{\circ}$ da lei que estabeleceu a criação da CNV atribuiu a ela o objetivo de “promover a reconciliação nacional” e o seu artigo $4^{\circ}, \S 4^{\circ}$ determinou que a comissão não teria "caráter jurisdicional ou persecutório", devendo respeitar, conforme destacado pelo artigo 6 ${ }^{\circ}$, "as disposições da Lei n 6.683, de 28 de agosto de 1979" [a Lei de Anistia] (BRASIL, 2011). Apesar disso, houve, durante todo o período de seu funcionamento, intensa disputa dentro da CNV acerca da inclusão ou não do tópico da responsabilização criminal de agentes da ditadura no seu Relatório final, com destaque para os posicionamentos públicos favoráveis nesse sentido dos conselheiros Paulo Sergio Pinheiro, Rosa Maria Cardoso da Cunha e Maria Rita Kehl. O documento final, lançado pela comissão em dezembro de 2014, acabou por incorporar na seção “Recomendações”, entre as “Medidas Institucionais", a crítica à Lei da Anistia por ser ela "incompatível com o direito brasileiro e a ordem jurídica internacional” e a defesa de sua revisão para aqueles que cometeram “crimes contra a humanidade, imprescritíveis e não passíveis de anistia", apesar da posição divergente de um dos conselheiros, José Paulo Cavalcanti Filho. O documento sustenta explicitamente a defesa da responsabilização "jurídica criminal, civil e administrativa - dos agentes públicos que deram causa às graves violações de direitos humanos ocorridas no período investigado pela CNV" (BRASIL, 2014).

\footnotetext{
7 A publicação do PNDH-3 ocorrida no final de 2009, particularmente, impulsionou diversas polêmicas e controvérsias, que repercutiram diretamente na forma como se deu posteriormente a criação da CNV. Há que se destacar, nesse sentido, as disputas em torno do trecho do documento que abordam a criação de uma Comissão da Verdade e que ocorreram no âmbito do próprio governo federal, envolvendo o Ministro da Defesa, Nelson Jobim e o Secretário de Direitos Humanos, Paulo Vannuchi. Sobre o tema, ver: DIEGUEZ (2011).
} 
Nos debates públicos, que ganharam novos contornos na sociedade brasileira desde o estabelecimento da CNV até a publicação do Relatório final, a imprensa desempenhou papel de enorme importância, buscando intervir nas disputas públicas de memórias que se colocaram em torno das interpretações e das representações sobre a ditadura inaugurada em 1964 e a redemocratização do país. Ao se analisar os editoriais da “grande imprensa” - em especial, aqueles publicados pelos jornais O Globo, Folha de São Paulo e O Estado de São Paulo -, percebe-se de que maneira essas publicações procuraram participar das controvérsias públicas sobre temáticas diversas relacionadas à CNV, posicionando-se em questões que iam desde a composição da comissão até o seu prazo de funcionamento, passando pela discussão do período a ser investigado pela Comissão devendo ele se concentrar na ditadura iniciada em 1964 ou também contemplar o período do Estado Novo. Porém, a maior parte dos editoriais publicados pelos três jornais esteve preocupada em discutir e em se posicionar em uma perspectiva contrária a qualquer iniciativa por parte da CNV que implicasse na revisão da Lei da Anistia, de 1979. A busca no sentido de "enquadrar" esse debate aproxima O Globo, a Folha e o Estadão, cujos editoriais, a despeito de pequenas variações, impuseram um mesmo tom na defesa da Lei da Anistia e na condenação a qualquer ação que pudesse ser interpretada como "revanchismo".

Antes mesmo da instituição da CNV, quando houve uma enorme repercussão pública em torno do PNDH-3, lançado em 2009, que sinalizava para a criação de uma comissão nos moldes daquela que foi posteriormente instituída, o jornal O Globo lançou, em 13 de janeiro de 2010, um editorial intitulado "Erro de avaliação", no qual já denunciava o "revanchismo" da "orwelliana" Comissão da Verdade proposta pelo governo Lula, colocando-se em uma posição contrária a qualquer movimento orientado na direção de rever a Lei da Anistia, de 1979, reabrindo “um capítulo já encerrado da história":

A orwelliana 'Comissão da Verdade', encharcada de revanchismo, é uma criação do governo Lula. Cabe, a propósito, registrar que nada se tem a opor que a sociedade consiga amplo acesso aos registros oficiais dos anos de chumbo, em especial os familiares dos mortos e desaparecidos. O inadmissível é revogar a anistia a favor de um lado, e com isso reabrir um capítulo já encerrado da história. Se o 'programa de direitos humanos' se 
resumir a um estratagema político, a fim de servir de toque de reunir para a esquerda, houve erro de cálculo. (O Globo, 13/01/2010, p. 6, grifos meus)

Em editorial publicado em 11 de março de 2011, com o título "Os militares e as vítimas da ditadura", o jornal O Globo deu sequência à crítica à criação de uma Comissão da Verdade, interpretando-a como uma demonstração de "insensibilidade política" por parte do governo Lula - com o apoio do Ministro dos Direitos Humanos, Paulo Vannuchi, e do Ministro da Justiça, à época da proposição do plano, Tarso Genro -, que teria permitido "que grupos da esquerda autoritária, incrustados no poder" levassem adiante "a revisão da Lei de Anistia, a fim de permitir a condenação na Justiça de agentes públicos autores de sequestros, tortura, assassinatos etc.". Para o jornal O Globo, a Lei da Anistia, reafirmada pelo STF, “foi recíproca”, ou seja, "perdoou militares, policiais e também passou a borracha no prontuário de terroristas e guerrilheiros". Ao se referir à polêmica que ocorreu quando, dias antes, o próprio jornal publicara uma reportagem com um documento escrito pelo Comando do Exército, com apoio da Marinha e da Aeronáutica, contra a criação da CNV, o editorial trouxe à tona a importância de se olhar para o outro lado da história, afirmando que os militares "não precisam se preocupar com o revanchismo, já descartado pela Justiça, mas têm razão ao reivindicar a apuração de crimes cometidos pela esquerda armada. A história precisa ser contada por inteiro" (O Globo, 11/03/2011, p. 6).

Entretanto, foi no dia 26 de setembro de 2011 que O Globo publicou um de seu editoriais mais fortes contra qualquer tentativa de revisão da Lei da Anistia por parte da CNV. De acordo com o jornal, em texto intitulado "Perdão negociado", a redemocratização teria sido "o fecho exitoso de uma longa e delicada negociação entre um regime nos estertores, mas ainda forte, e a oposição, em busca de um objetivo mais do que meritório: uma transição sem violência". Trata-se de um elogio explícito ao "gradualismo e a intensa negociação entre o poder vigente e oposicionistas", que "iriam dar um caráter de moderação à anistia, concedida, portanto, a ambos os lados". Para o jornal, a vitória de Lula, em 2002, teria levado a Brasília “militantes da esquerda armada do final da década de 60/início dos anos 70", grupo esse que tentou, a partir do segundo mandato de Lula, "abrir uma brecha para rever a Lei de Anistia, por meio do programa 
nacional de defesa dos direitos humanos". O editorial procura reafirmar a importância da CNV "para obter informações sobre o paradeiro de pessoas desaparecidas naquela guerra suja, jogar luz em episódios obscuros", bem como "informar a famílias e amigos o destino das vítimas, assim como relatar para a História aquela época dramática, a fim de que ela não se repita". Porém, se coloca frontalmente contrário à tentativa de "converter a comissão num tribunal de acusação", que "além de ilegal, seria contrariar o processo de redemocratização" (O Globo, 26/09/2011, p. 6).

Em editorial intitulado “A Comissão da Verdade”, publicado pelo jornal O Estado de São Paulo em 02 de outubro de 2011, o periódico também defende a Lei da Anistia e problematiza qualquer iniciativa que busque colocar em cheque a "reconciliação nacional" representada por aquela lei. O texto se estrutura em volta da crítica ao fato de a CNV ter aberto uma possibilidade para que diversos grupos tentassem "abrir brechas na Lei da Anistia, a partir de uma perspectiva unilateral”. Apesar da ressalva, o texto elogia “a maneira como a Comissão está sendo construída”, parecendo "indicar que o bom senso afinal prevalecerá, em benefício do objetivo maior de reconciliação nacional e da construção de um futuro assentado em bases de convivência democrática". De acordo com o editorial, a CNV deveria manter-se focada exclusivamente na investigação sobre o passado, na medida em que "a Lei da Anistia colocou um ponto final" em qualquer discussão sobre "a possibilidade de levar a julgamento agentes do Estado responsáveis por mortes, torturas e desaparecimento" (O Estado de São Paulo, 02/10/2011, p. A3).

A instalação oficial da CNV em 16 de maio de 2012 suscitou novos editoriais dedicados aos trabalhos da comissão. Nesse mesmo dia, da posse dos sete integrantes da CNV, o editorial do jornal O Globo, com o título "O que se espera da Comissão da Verdade", saudou a composição heterogênea da mesma - "Se a psicanalista Maria Rita Kehl pode ser considerada próxima ao PT, há um ex-ministro da Justiça e um exsecretário de Direitos Humanos de FH, José Carlos Dias e Paulo Sérgio Pinheiro" - e a moderação da proposta aprovada, que, ao contrário daquela divulgada no PNDH-3, que "surgiu contaminada pela visão revanchista de alguns setores do governo", apontou para o respeito à Lei de Anistia, que teria beneficiado “os dois lados", tendo sido o resultado “de uma ampla negociação entre líderes da oposição e os generais, ao contrário do que 
aconteceu em outros países latino-americanos". O mérito da CNV, portanto, estaria em promover uma investigação do passado "sem revanchismo", que conformaria a "maturidade política" do país: "O Brasil, assim como retirou por impeachment um presidente do Planalto, sem uma vidraça estilhaçada nas ruas, conseguiu fazer uma transição de volta à democracia também sem violência" (O Globo, 16/05/2012, p. 6). No dia 13 de maio de 2012, o jornal O Estado de São Paulo publicou o editorial intitulado "A Comissão escalada" elogiando a criação e a escolha dos integrantes da Comissão, porém ressaltando que a ela caberia investigar o passado, inclusive dando aos agentes públicos “a oportunidade de contar o que fizeram”, sem, é claro, “o risco de pagar por seus atos”, o que implicaria em uma revisão da Lei da Anistia (O Estado de São Paulo, 13/05/2012, p. A3). Em 18 de maio do mesmo ano, O Estado de São Paulo retornou ao tema, e publicou um editorial intitulado "Uma fala exemplar”, no qual elogia o discurso de Dilma Rousseff naquela ocasião, sobretudo pelo fato de ela reafirmar, ainda que implicitamente, a defesa da Lei da Anistia, ao destacar que a CNV não foi criada movida pelo "revanchismo". De acordo com o jornal, os esforços direcionados para a investigação dos crimes cometidos no passado são necessários e não devem ter "por objetivo derrogar a Lei da Anistia, de 1979" (O Estado de São Paulo, 18/05/2012, p. A3).

A Folha de São Paulo publicou, em 25 de maio de 2013, o editorial intitulado "Em defesa da Anistia" com tom semelhante na crítica ao "revanchismo" e à tentativa de rediscutir uma decisão referendada pelo STF, em 2010, referente à Lei da Anistia, de 1979. O documento teria se mostrado "profícuo, com o passar do tempo", refreando "ímpetos que poderiam levar a um processo de aprofundamento de conflitos e divisões, em prejuízo do reencontro da sociedade consigo mesma e com a reconstrução da democracia ora consolidada, de maneira inédita na história do país". Ao invés de "uma imposição", a "anistia ampla foi um pacto que assegurou a transição democrática", que estaria diretamente vinculada à "tradição brasileira da reconciliação", que, ao invés de ser interpretada "como sinal de fraqueza histórica", deveria ser compreendida como algo de enorme importância, tendo "contribuído para que o país não se dilacere em lutas internas". O editorial foi motivado pela manifestação de alguns dos membros da CNV a favor da revisão da lei de 1979, após um evento que comemorou um ano de trabalho da comissão. De acordo com o jornal: 


\begin{abstract}
No que tange à proposta de mudar a Lei da Anistia, trata-se de recorrente e rematado equívoco, cujas repercussões danosas se fazem pressentir em vários níveis. Já de início, declarações nesse sentido, a um ano do encerramento das pesquisas, fomentam a discórdia no próprio grupo, uma vez que alguns de seus membros são contrários à proposta. Ao mesmo tempo, reaviva-se a desconfiança de que os trabalhos em curso se pautem pelo espírito de revanchismo, o que por sua vez alimenta a reticência de representantes das Forças Armadas que resistem, muitas vezes de maneira inaceitável, a colaborar com as requisições da comissão. [...]. A Comissão da Verdade faz um trabalho valioso de restabelecimento de fatos históricos. Deveria se concentrar em sua tarefa em vez de abraçar propostas inoportunas que extrapolam o seu próprio escopo. (Folha de São Paulo, 25/05/2013, p. A2, grifos meus)
\end{abstract}

Em diferentes editoriais publicados ao longo dos trabalhos da CNV, a Folha de São Paulo buscou reiterar a defesa à Lei da Anistia e se posicionar contra qualquer tentativa que buscasse uma revisão da mesma. Em 26 setembro de 2012, quando da divulgação da notícia segundo a qual no documento de óbito de Vladmir Herzog - por iniciativa da viúva Clarice Herzog e da Comissão da Verdade - passaria a constar que sua morte decorreu de lesões e maus-tratos nas dependências do Exército, a Folha de São Paulo publicou um editorial destacando que ações no sentido de "esclarecer os fatos e reconstituir a memória" deveriam ser aquelas a orientar os trabalhos da CNV, e não ações no sentido de rever a Lei da Anistia. Conforme destacado pelo jornal: “À luz do espírito conciliatório da Anistia, os atos da comissão não podem legalmente se revestir de caráter jurisdicional, para condenar ou para absolver" (Folha de São Paulo, 22/09/2012, p. A2). Em editorial publicado em 20 de setembro de 2014, intitulado "Primeiro passo", o jornal reforça a ideia segundo a qual: "O principal mérito da Lei da Anistia, promulgada em 1979, foi o de permitir que o processo de democratização do país se desse num clima desanuviado dos ressentimentos que pesavam sobre ambas as partes em conflito" (Folha de São Paulo, 20/09/2014, p. A2).

O jornal O Globo voltaria à defesa da Lei da Anistia em diferentes momentos, com destaque para dois editoriais publicados em 2014. Em 25 de setembro daquele ano, em editorial intitulado "Limites da Comissão Nacional da Verdade", o jornal, além de defender a ideia de que, “para ser isenta, a comissão deveria, na busca pela 'verdade', também registrar a história de vítimas de movimentos radicais de esquerda", retoma a defesa de se avançar no conhecimento do passado "sem fins judiciais". Embora 
valorizasse a importância da iniciativa do então ministro da Defesa, Celso Amorim, no sentido de encaminhar um ofício à CNV, reconhecendo formalmente a responsabilidade do Estado nas violações dos direitos humanos durante o período da ditadura, o editorial critica aqueles que defendem a ideia de que caberia às Forças Armadas um pedido de desculpas formal às vítimas do arbítrio, na medida em que esse gesto, uma vez mais, estaria vinculado à busca por "revanchismos". Como destacado pelo jornal: "E também não cabe qualquer pedido de desculpas dos militares, pois já é evidente o reconhecimento de erros pelo Estado. O passado tem de ser conhecido para que não se repita no futuro. Mas sem revanchismos, como prevê a anistia" (O Globo, 25/09/2014, p. 22).

Em um editorial ainda mais direto, publicado em 02 de dezembro de 2014, com o título "Uma visão unilateral da Lei da Anistia", ainda antes da divulgação do Relatório final da CNV, O Globo reafirma sua posição em defesa da Lei, "concedida de forma recíproca em 1979", resultado da "bem-sucedida negociação entre generais e a oposição, àquela época, sancionada livremente pelo Congresso". O jornal adianta que "não se espera um relatório equilibrado", prevendo que “o viés que deverá ter o relatório deriva da própria contaminação ideológica do processo de criação da Comissão", que remontaria ao PNDH-3. O jornal lamenta que, a despeito de algumas resistências, "os grupos mobilizados para rever o alcance da Lei da Anistia, confirmada pelo próprio Supremo, continuam a agir". De acordo com o editorial, se revisão deve haver, ela também deve ser direcionada para os "crimes cometidos pela chamada esquerda armada", dando como exemplos o "assassinato do tenente Mendes a coronhadas de fuzil, por um grupo da Vanguarda Popular Revolucionária (VPR) comandado pelo capitão Carlos Lamarca, desertor do Exército", a "morte do soldado Mario Kozel Filho, num atentado contra o Comando Militar de São Paulo, de autoria da mesma VPR" e o assassinato "de outro militar, Orlando Lovecchio, ferido por bomba no consulado paulista dos Estados Unidos". O Globo conclui seu editorial criticando a tentativa de se rever o passado em busca de "vencedores" e "vencidos", com o intuito de modificar a Lei da Anistia: “No caso da 'guerra suja' brasileira, não será positivo que o relato a ser apresentado pressuponha que houve 'vencidos', quando aquela transição surgiu de um 
pacto entre contrários. Se isso acontecer, e a depender da reação do Planalto, ficará configurada a tentativa de se reescrever o passado".

A divulgação do Relatório final da CNV, que estabelecia em suas "Recomendações", conforme destacado no início desta seção, a revisão da Lei da Anistia por ser ela "incompatível com o direito brasileiro e a ordem jurídica internacional”, gerou reações mais fortes por parte dos três órgãos da "grande imprensa". Em editoriais publicados no dia 11 de dezembro de 2014, os jornais O Estado de São Paulo e O Globo se posicionaram em uma perspectiva contrária à revisão da Lei da Anistia tal qual defendido pelo Relatório final da CNV. Em editorial, intitulado "O trabalho de uma comissão", O Estado de São Paulo criticou o documento divulgado pela comissão, tanto por buscar “reescrever a história daquele período conforme uma narrativa que não só ignora os crimes da esquerda armada, como a transforma em mártir da democracia”, quanto por sua "versão parcial dos fatos", que aponta não para uma "reconciliação", mas para "um acerto de contas", ao defender a revisão da Lei da Anistia. Para o jornal, o "espírito que moveu a Comissão da Verdade" se contrapõe ao "espírito daquela lei” de 1979, que buscava não propriamente "perdoar crimes”, mas "deixá-los no passado, no âmbito da história, para que a transição do regime militar para a democracia se desse de forma pactuada, evitando o revanchismo que inviabilizaria a reconciliação". Para O Estado de São Paulo, o que se constituiu, desde o início, foi "uma comissão que se arrogou o papel de tribunal da história para efetuar um julgamento que, segundo entendem seus promotores, foi indevidamente protelado pela Lei de Anistia" (O Estado de São Paulo, 11/12/2014, p. А3).

No mesmo dia, o jornal O Globo publicou o editorial "Comissão extrapola ao pedir limitação da Lei da Anistia", no qual sustenta a ideia de que "a expectativa de que haveria uma carga contra a Lei da Anistia, negociada na transição da ditadura militar para a democracia, por generais e líderes políticos da oposição, foi confirmada ontem na entrega formal do trabalho à presidente". O jornal elogia a presidenta Dilma Rousseff pela sua "sensata mensagem" ao receber o Relatório final, por ter se posicionado contra a revisão do passado e a favor dos "pactos políticos que nos levaram à democracia". “Mesmo presa e torturada, por atuar em um grupo armado de resistência ao regime", 
ressalta o editorial, Dilma teria dado “demonstração de extremo equilíbrio ao afirmar, na solenidade de recebimento do relatório, que 'a verdade não significa revanchismo [...], nem deve ser motivo para ódio ou para acerto de contas"”. Para O Globo, contudo, “escapou a cinco dos seis componentes da CV que a Lei da Anistia, de 1979, vai além do perdão recíproco: ela é a expressão legal do entendimento entre militares e oposição em torno de um projeto de redemocratização sem violência". Após elogiar o posicionamento do conselheiro José Paulo Cavalcanti Filho, reafirma que tratados internacionais dos quais o país é signatário “não estão acima da Constituição” (O Globo, 11/12/2014, p. 18).

No dia seguinte, 12 de dezembro de 2014, foi a vez do jornal Folha de São Paulo manifestar em seu editorial, com o título "Página virada”, sua posição crítica ao Relatório final da CNV, reiterando a defesa da "anistia irrestrita" como "um dos pilares sobre os quais se apoia a democracia brasileira". A despeito de reconhecer que "falta às Forças Armadas divulgar os documentos retidos e reconhecer os abusos praticados", o editorial segue argumento parecido àquele defendido pelo jornal O Globo, posicionando-se ccontrariamente à tentativa de alterar a Lei da Anistia por pressão de organismos internacionais, a exemplo da Corte Interamericana de Direitos Humanos:

Não é sensato nem desejável que compromissos internacionais assumidos pelo Brasil, determinando que a tortura é crime imprescritível, possam sobrepor-se à soberania jurídica nacional quando se trata das próprias fundações do Estado de Direito entre nós. A anistia deve ser preservada. O passado precisa ser conhecido e debatido. (Folha de São Paulo, 12/12/2014, A2, grifos meus)

No dia 15 de dezembro de 2014, no editorial “Ampla e irrestrita”, o jornal O Globo voltou à discussão suscitada pela divulgação do Relatório final da CNV. Embora elogiasse os trabalhos da comissão, que "rasgou o incômodo véu que procurava manter encobertos episódios obscuros da ditadura militar, inclusive apontando responsabilidades no topo da hierarquia militar e também iluminando os porões, com a identificação de agentes públicos envolvidos em torturas e outros atos condenáveis contra opositores ao regime", o jornal retoma a crítica ao documento final em decorrência de sua defesa da revisão da Lei da Anistia. O editorial chama a decisão de “lamentável”, “oportunista” e a define como uma "perigosa extrapolação”, por ir em 
sentido contrário a uma lei que "apostou na conciliação, e não no confronto, muito menos na violência ou em radicalismos revanchistas". O Globo reafirma mais uma vez que os "tratados internacionais que condenam crimes como a tortura [...] não se sobrepõem à Constituição do país" e que, se alguma punição deve ocorrer, ela também deve se direcionar aos "militantes da esquerda envolvidos no assassinato de agentes públicos", não se restringindo a "apenas um lado da 'guerra suja”" (O Globo, 15/12/2014, p. 14).

\section{Conclusão}

Desde o momento em que houve um movimento mais concreto orientado para a criação de uma Comissão da Verdade, a partir do PNDH-3, os debates públicos em torno da Lei da Anistia de 1979 foram reavivados com enorme força, com diferentes atores sociais e coletivos participando das controvérsias em torno do tema. O estabelecimento efetivo da CNV, o início dos seus trabalhos e, sobretudo, a publicação do "Relatório final", colocaram esses debates em outro patamar, e os conflitos de memórias sobre as características da ditadura, inaugurada em 1964, e da transição democrática, ganharam espaço na esfera pública do país e se converteram em assuntos atravessados por enorme tensão. O que busquei demonstrar neste artigo, a partir da análise dos editoriais publicados pelos jornais O Globo, Folha de São Paulo e O Estado de São Paulo, foi de que maneira a "grande imprensa" se colocou como um ator fundamental nessas disputas de “memórias conflitantes” na esfera pública, mediante a construção de determinado “enquadramento" sobre o passado, voltado para a defesa da manutenção da Lei da Anistia.

Não se trata de dizer que os três jornais compartilharam exatamente da mesma visão em relação aos trabalhos da CNV e às suas conclusões, nem mesmo em relação à ditadura inaugurada com o golpe de 1964 e ao processo de transição democrática, mas sim de afirmar, a partir da empiria analisada, que, a despeito de eventuais divergências e variações de posição, O Globo, Folha de São Paulo e O Estado de São Paulo adotaram o mesmo tom em relação à temática. A análise dos editoriais publicados durante o período de trabalho da comissão permite confirmar a hipótese de que esses órgãos da "grande imprensa" construíram um enquadramento semelhante sobre o assunto e sustentaram 
posições uniformes na crítica a qualquer movimento realizado pela CNV que buscasse rever a Lei da Anistia.

Apesar da retórica da neutralidade e da imparcialidade, os meios de comunicação realizam seleções e recortes não apenas em relação a temáticas do tempo presente, mas também de assuntos referentes ao passado. Esses enquadramentos - sobretudo quando construídos de forma uniforme pela "grande imprensa" - têm consequências diretas sobre a forma como períodos históricos são debatidos na esfera pública, na medida em que implicam na construção de determinadas "memórias hegemônicas", que acabam por silenciar outras memórias, que não possuem a mesma condição de intervir nas controvérsias públicas sobre o passado. Em tempos conturbados como os dias de hoje, nos quais a retórica em defesa do retorno da ditadura e de soluções autoritárias se torna cada vez mais frequente entre diferentes setores sociais, e nos quais determinados discursos tentam sustentar que um golpe parlamentar foi um processo democrático, 0 aprofundamento da reflexão sobre as relações entre mídia, memória e usos públicos do passado se torna uma tarefa não apenas necessária, mas urgente.

\section{Referências}

AARÃO REIS FILHO, Daniel. Ditadura, anistia e reconciliação. Estudos Históricos, Rio de Janeiro, v. 23, p. 171-186, 2010.

AQUINO, Maria Aparecida. Censura, imprensa, estado autoritário, 1968-1978: o exercício cotidiano da dominação e da resistência. Bauru: Edusc, 1999.

BARAHONA DE BRITO, Alexandra. Justiça de transição em câmara lenta: o caso do Brasil. In: PINTO, Antonio Costa ; MARTINHO, Francisco Palomanes (Orgs.). O Passado que não passa: a sombra das ditaduras na Europa do Sul e América Latina. Rio de Janeiro: Civilização Brasileira, 2013, p. 235-250.

BAUER, Caroline Silveira. Como será o passado?: história, historiadores e a Comissão Nacional da Verdade. Jundiaí: Paco Editorial, 2017. 
BIROLI, Flávia. Representações do golpe de 1964 e da ditadura na mídia: sentidos e silenciamentos na atribuição de papeis à imprensa, 1984-2004. Varia História, Belo Horizonte, v. 25, p. 269-291, 2009.

BRASIL, Lei n. 12.528 de 18 de novembro de 2011. Cria a Comissão Nacional da Verdade no âmbito da Casa Civil da Presidência da República. Brasília: Presidência da República [2011]. Disponível em: http://www.planalto.gov.br/ccivil_03/_ato2011-2014/2011/lei/l12528.htm. Acesso em: 10 mai. 2018.

BRASIL. Relatório da Comissão Nacional da Verdade. Brasília: CNV, 2014. Disponível em: http://www.cnv.gov.br/images/pdf/relatorio/Capitulo\%2018.pdf. Acesso em: 05 jun. de 2018.

CAPELATO, Maria Helena. Imprensa como fonte para a história do tempo presente. In: FERREIRA, Marieta de Moraes; DELGADO, Lucília de Almeida Neves (Orgs.). História do Tempo Presente. Rio de Janeiro: FGV Editora, 2014, p. 299-315.

CARVALHO, Alessandra. "Contando a história" da ditadura civil-militar: grande imprensa e a construção da memória no Brasil democrático. In: QUADRAT, Samantha Viz ; ROLLEMBERG, Denise (Orgs.). História e memória das ditaduras do século XX. Rio de Janeiro: FGV Editora, 2015, p. 394-424.

DEARING, James W.; ROGERS, Everett M. Agenda-setting. Thousand Oaks: Sage, 1996.

DIEGUEZ, Consuelo. “Para toda obra”. Revista Piauí, São Paulo, n. 59, ago. 2011.

Disponível em: http://piaui.folha.uol.com.br/materia/para-toda-obra/. Acesso em: 15 de jun. 2016.

FERES JR. João et. al. Administrando o debate público: O Globo e a controvérsia em torno das cotas raciais. Revista Brasileira de Ciência Política, Brasília, n. 11, p. 7-31, 2013.

FICO, Carlos. “Prezada Censura”. Cartas ao regime militar”. Topoi, Rio de Janeiro, n.5, 2002, p.251-86.

FICO, Carlos. História do tempo presente, eventos traumáticos e documentos sensíveis: o caso brasileiro. Varia História, Belo Horizonte, v. 28, 2012, p.43-59.

HUYSSEN, Andreas. Seduzidos pela memória: arquitetura, monumentos, mídia. Rio de Janeiro: Aeroplano, 2000.

HUYSSEN, Andreas. Culturas do passado-presente: modernismos, artes visuais, políticas da memória. São Paulo: Contraponto, 2014.

KUSHNIR, Beatriz. Cães de guarda: jornalistas e censores, do Al-5 à Constituição de 1988. São Paulo: Boitempo, 2004. 
LEE, Phillip; NINAN, Pradip (Eds.). Public memory, public media, and the politics of justice. New York: Palgrave Macmillan, 2012.

MACIEL, Suellen N. P. Disputas da memória: uma reflexão inicial sobre a lei de criação da Comissão Nacional da Verdade. In: DELGADO, Lucília de Almeida Neves; FERREIRA, Marieta de Moraes (Orgs.), História do Tempo Presente. Rio de Janeiro: Editora FGV, 2014, p. 116-133.

McCOMBS, Maxwell; SHAW, Donald. The agenda-setting function of mass media. The Public Opinion Quarterly, Oxford, v. 36, n. 2, p. 176-187, 1972.

MIGUEL, Luis Felipe \& BIROLI, Flávia. A produção da imparcialidade: a construção do discurso universal a partir da perspectiva jornalística. Revista Brasileira de Ciências Sociais, v. 25, p. 59-76, 2010.

MOTTA, Rodrigo Patto Sá. Entre a liberdade e a ordem: o jornal O Estado de São Paulo e a ditadura (1969-1973). Estudos Ibero-Americanos, Porto Alegre, v. 43, p. 367-379, 2017.

NAPOLITANO, Marcos. A imprensa e a construção da memória do regime militar brasileiro (1965-1985). Estudos Ibero-Americanos, Porto Alegre, v. 43, p. 346-366, 2017.

NEIGGER, Motti et. all (eds.). On media memory: collective memory in a new media age. Hampshire: Palgrave Macmillan, 2011.

NEVES, Rafael. Uma Comissão da Verdade no Brasil? Desafios e perspectivas para integrar direitos humanos e democracia. Lua Nova, São Paulo, n. 85, p. 155-185, 2012.

PEREIRA, Matheus. Nova Direita? Guerras de memória em tempos de Comissão da Verdade (2012-2014). Varia História, Belo Horizonte, v. 31, p. 863-902, 2015.

PERLATTO, Fernando; HOLLANDA, Cristina Buarque. Entre a reconciliação e a justiça: a Lei da Anistia diante das Comissões da Verdade" ; In: ARAUJO, Maria Paula; PINTO, António Costa (Orgs.). Democratização, memória e justiça de transição nos países lusófonos. Pernambuco: EDUPE, 2017, p.16-30.

POLLAK, Michael. Memória, esquecimento, silêncio. Estudos Históricos, Rio de Janeiro, v.2, n.3, p.3-15, 1989.

RODEGHERO, Carla Simone. A anistia de 1979 e seus significados ontem e hoje. In: REIS, Daniel Aarão et. al (Orgs.). A ditadura que mudou o Brasil: 50 anos do golpe de 1964. Rio de Janeiro: Zahar, 2014, p. 172-185.

ROLLEMBERG, Denise. As trincheiras da memória. A Associação Brasileira de Imprensa e a ditadura (1964-1974). In: ROLLEMBERG, Denise; QUADRAT, Samantha Viz (Orgs.). A 
construção social dos regimes autoritários: legitimidade, consenso e consentimento no Século XX. v. 2. Rio de Janeiro: Civilização Brasileira, 2010, p. 97-144.

SCHNEIDER, Ann. Legislative efforts against impunity in the 1979 Amnesty debate in Brazil. Bulletin of Latin America Research, v. 37, n. 1, p. 18-32, 2018.

TODOROV, Tzvetan. Los abusos de la memoria. Barcelona: Ediciones Paidós Ibérica, 2000.

Recebido em 22/05/2018 Aprovado em 11/02/2019 